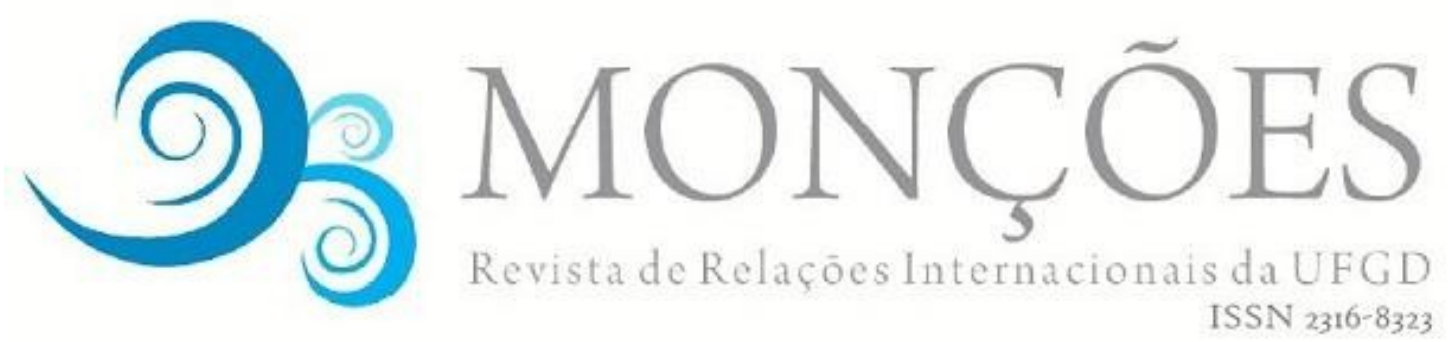

\title{
O ATIVISMO JURÍDICO TRANSNACIONAL NO SISTEMA INTERAMERICANO DE DIREITOS HUMANOS: UM ESTUDO SOBRE A MOBILIZAÇÃO NO CHILE EM TORNO DA PROMOÇÃO DA JUSTIÇA DE TRANSIÇÃO.
}

THAIS MARIA DELARISSE

Mestranda em Relações Internacionais no Instituto de Economia e Relações Internacionais - IERI-UFU e pesquisadora do Núcleo de Pesquisas e Estudos em Direitos Humanos do

IERI-UFU.

MARRIELLE MAIA ALVES FERREIRA

Doutora em Política Internacional pelo Instituto de Filosofia e Ciências Humanas IFICH/UNICAMP; mestre em Relações Internacionais pelo IREL/UnB; especialista em Direitos Humanos pela UnB, Universidade de Essex e ESMPDFT. Atua como coordenadora do Núcleo de Pesquisa e Estudos em Direitos Humanos do IERI-UFU e do Instituto Nacional de Ciência e Tecnologia para Estudos sobre os Estados Unidos - INCT/INEU. É professora dos cursos de pós-graduação e graduação em Relações Internacionais do Instituto de

Economia e Relações Internacionais da Universidade Federal de Uberlândia.

RESUMO: O presente artigo tem como objetivo fazer um estudo sobre a advocacy transnacional, por meio de um estudo de caso sobre a mobilização chilena no Sistema Interamericano de Direitos Humanos (SIDH), em torno da temática de justiça de transição. Nesse sentido, busca-se argumentar que o caso chileno foi o percurso em relação a advocacy transnacional na América Latina. Para tanto, foram analisados as informações disponíveis na base de dados do SIDH sobre os Estados sulamericanos do Núcleo de Pesquisa e Estudos em Direitos Humanos da Universidade Federal de Uberlândia (NUPEDH-IERIUFU), sobre os casos processados contra o Estado chileno, com o propósito de analisar o perfil de mobilização contra o referido Estado na Comissão Interamericana de Direitos Humanos. As dinâmicas institucionais e a mobilização do ativismo transnacional, com vistas a alcançar efeitos normativos e estratégicos, foram estudados levando em consideração o contexto de disputa e o uso de oportunidades políticas, tanto para ressignificar as normas como para influenciar a política doméstica.

PALAVRAS-CHAVE: Chile, SIDH, Justiça de Transição.

THE TRANSNATIONAL LEGAL ACTIVISM IN THE INTER-AMERICAN SYSTEM ON HUMAN RIGHTS: A STUDY ABOUT THE CHILEAN MOBILIZATION AROUND THE PROMOTION OF TRANSITIONAL JUSTICE 


\begin{abstract}
The purpose of this article is to study transnational advocacy through a case study on Chilean mobilization in the Inter-American System on Human Rights (IASHR) on the theme of transitional justice. In this sense, we seek to argue that the Chilean case was the precursor in relation to transnational advocacy in Latin America. In order to do so, the information available in the IASHR's database about the South American States of the Center for Research and Studies in Human Rights of the Universidade Federal de Uberlândia (NUPEDH-IERIUFU) on the cases brought against the Chilean State were studied, in order to analyze the profile of the mobilization against the State in the Inter-American Commission on Human Rights. Institutional dynamics and the mobilization of transnational activism, with a view to achieving normative and strategic effects were studied taking into account the context of dispute and the use of political opportunities, both to re-standardize and to influence domestic politics.
\end{abstract}

KEY-WORDS: Chile; IASHR; Transitional Justice.

\title{
1. Introdução
}

Durante os anos 1990 os mecanismos jurisdicionais internacionais passaram por uma considerável ampliação, de forma similar o ativismo jurídico transnacional ${ }^{1}$ também vivenciou o desenvolvimento de sua significância. Diante deste contexto, Lutz e Sikkink (2001) interpretaram essas características como pertencentes a um fenômeno mais amplo, nomeado por elas como cascata de justiça.

Frente a essa conjuntura, as redes de advocacy ganharam relevância, na medida em que se valeram de oportunidades políticas, proporcionadas pelos organismos internacionais, para levar adiante demandas da sociedade civil que através das estruturas domésticas não conseguem prosperar. Sendo assim, as redes adotam uma dinâmica que permite a ressignificação de normas de direitos humanos em contexto conflituosos, no qual o Estado é ao mesmo tempo o violador e o principal responsável pela garantia dos direitos fundamentais.

A partir da constatação da relevância das redes de advocacy para a litigância internacional, Santos (2007) argumenta na essencialidade de se investigar as práticas dos defensores jurídicos transnacionais, com o intuito de melhor compreender como os atores da sociedade civil se engajam na mobilização jurídica transnacional. Do mesmo modo, com a finalidade de assimilar "como o Estado se

\footnotetext{
${ }^{1}$ Santos (2007, p. 28) define ativismo jurídico transnacional como o "ativismo focado na ação legal engajada, através de cortes internacionais ou instituições quase judiciais, em fortalecer as demandas de movimentos sociais; realizar mudanças legais e políticas internas; reestruturar ou redefinir direitos; e/ou pressionar os Estados a cumprir normas internacionais e internas de direitos humanos".
} 
refere às normas internacionais de direitos humanos e como os discursos e práticas ligados aos direitos humanos são desenvolvidos em diferentes setores do Estado e em diversos níveis da atuação estatal" (SANTOS, 2007, p. 28).

As normas, por conseguinte, são tidas, de acordo com a interpretação de Benford e Snow (2000), como quadros interpretativos que sintetizam e codificam os problemas, de forma a permitir que a complexidade social possa ser manejada pelo indivíduo como situação que requer mobilização.

A partir disso, reconhece-se os mecanismos judiciais e quase judiciais do Sistema Interamericano de Direitos Humanos (SIDH) como instâncias abertas a mobilização do direito, como parte da construção da própria identidade e de uma estratégia do ativismo para alcançar seus interesses e valores. Ademais, concebese essas estruturas como atores, cujas atuações modelam as estratégias de outros poderes e sujeitos nas disputas que ocorrem na arena pública.

Em vista disso, o presente trabalho visa contribuir para os estudos sobre a advocacy transnacional, a partir de um estudo de caso sobre a mobilização chilena no Sistema Interamericano de Direitos Humanos, no que se refere à justiça de transição como forma de alcançar o direito à verdade e à justiça. Nesse sentido, argumenta-se que o caso chileno foi o percursor da advocacy transnacional na América Latina e, dessa forma, tornou-se uma referência regional neste assunto.

A partir de dados coletados na base de dados do Sistema Interamericano de Direitos Humanos - elaborada no âmbito do Núcleo de Pesquisa e Estudos em Direitos Humanos do Instituto de Economia e Relações Internacionais da Universidade Federal de Uberlândia (NUPEDH - IERIUFU) ${ }^{2}$ - é possível demonstrar as estratégias de mobilização adotadas pelos atores, durante o processo de litigância no Sistema Interamericano de Direitos Humanos, bem como a interação entre os ativistas, o SIDH e o Estado.

\footnotetext{
${ }^{2} \mathrm{O}$ banco de dados reúne informações sobre os casos analisados pelo SIDH entre os anos de 1971 à 2015. Nesse sentido, compreende os casos denunciados contra países sulamericanos de acordo com a seguinte distribuição: Argentina (172 na CIDH e 16 na CtIDH), Bolívia (40 na CIDH e 6 na CtIDH), Brasil (117 na CIDH e 6 na CtIDH), Chile (104 na CIDH e 8 na CtIDH), Colômbia (155 na $\mathrm{CIDH}$ e 15 na CtIDH), Equador (141 na CIDH e 17 na CtIDH), Paraguai (58 na CIDH e 7 na CtIDH), Peru (317 na CIDH e 37 na CtIDH), Suriname (19 na CIDH e 6 na CtIDH), Uruguai (18 na CIDH e 2 na CtIDH) e Venezuela (68 na CIDH e 19 na CtIDH).
} 
Com esse intuito, o trabalho está dividido em 4 seções além da introdução e conclusão. A primeira visa elucidar o papel do Sistema Interamericano de Direitos Humanos na região; a seção seguinte tem como objetivo apresentar as características do processo de justiça de transição visualizado na América Latina; a parte subsequente descreve o contexto chileno, o qual contribuiu para a emergência da mobilização em torno da situação dos direitos humanos no país; e, por fim, o último segmento visa analisar a litigância, em torno do caso chileno no Sistema Interamericano.

\section{O Sistema Interamericano de Direitos Humanos: o papel de protetor dos direitos humanos na região}

O Sistema Interamericano foi constituído no âmbito da Organização dos Estados Americanos (OEA) com a afirmação da Declaração Americana dos Direitos e Deveres do Homem e o estabelecimento da Carta da Organização dos Estados Americanos, ambos em 1948. O SIDH é formado por dois órgãos principais, a Comissão Interamericana de Direitos Humanos (CIDH) e a Corte Interamericana de Direitos Humanos (CtIDH).

A Comissão Interamericana, primeiro órgão do SIDH, tinha a princípio apenas a competência de promover os direitos humanos na região, entretanto, aos poucos foi se transformando também em um órgão protetivo ${ }^{3}$. No ano de 1959, a Declaração de Santiago afirmou a importância do estabelecimento de mecanismos para a garantia dos direitos humanos e no ano de 1960 o Conselho da OEA aprovou o estatuto da CIDH (DYKMANN, 2007; GOLDMANN, 2009).

A criação da CtIDH ocorreu anos depois, inclusive, após longos debates sobre a conveniência da própria Convenção Americana sobre Direitos Humanos

\footnotetext{
${ }^{3} \mathrm{~A}$ CIDH é a entidade política do SIDH, a qual atua como órgão receptor de denúncias no sistema de petições, além de possuir um mecanismo de relatorias que visa o monitoramento do cumprimento dos direitos humanos na região das Américas. Em relação ao sistema de petições, a CIDH é responsável pela recepção e análise de admissibilidade e mérito das denúncias, além de ser a encarregada por encaminhar os casos à Corte. Qualquer indivíduo, ou grupo de indivíduos, pode encaminhar denúncias à $\mathrm{CIDH}$, essa é uma das razões que permite com que as redes de advocacy encontrem no SIDH um espaço relevante e estratégico de pressão aos Estados para o cumprimento de suas obrigações internacionais (OEA, 2015).
} 
(CADH), frente à relutância de alguns Estados, em razão da possibilidade de conflito entre os tratados da Organização das Nações Unidas e a minuta da Convenção Americana. Superados os debates, a CADH foi aprovada no ano de 1969 e entrou em vigor em 1978, após a sétima ratificação do tratado (GOLDMANN, 2009). É no texto da Convenção que consta a previsão da criação de uma Corte com competência para julgar os casos de direitos humanos de Estados que aceitem sua jurisdição ${ }^{4}$.

O histórico de institucionalização do SIDH foi cercado por contradições próprias de um contexto marcado pela Guerra Fria, assim como pelo existência de regimes autoritários no continente. Desse modo, por um lado se observou uma forte influência dos Estados Unidos, os quais visavam privilegiar o combate ao comunismo. E, por outro lado, o impacto dos demais Estados da região, que tinham o interesse de reforçar o princípio da não intervenção (CARLETON; STOHL, 1987; GOLDMAN, 2009; ROMANO, 2009, MAIA, 2017).

Assim, a estrutura e a atuação da Comissão e da Corte foram sendo moldadas e remodeladas de acordo com as oportunidades ${ }^{5}$. Desse modo, o amparo legal para a atuação dos órgãos do Sistema foi sendo garantido com o decorrer do tempo, em meio às disputas políticas que envolviam os Estados, grupos de ativistas e a própria organização. $O$ fato é que desde a criação do $\mathrm{SIDH}$, a Comissão é o único fórum para a apresentação de denúncias individuais e coletivas de violações aos direitos humanos perpetradas pelos Estados.

Sua abertura à atuação das redes de advocacy é interpretada como uma característica que reforça o papel do Sistema como uma importante instância decisória e, portanto, como um ator relevante no processo de mobilização do direito, especialmente na promoção de mecanismos de justiça de transição na América

\footnotetext{
${ }^{4}$ A CtIDH é o órgão jurisdicional do Sistema com competência consultiva e contenciosa, podendo ser acionada pelos Estados membros e pela CIDH. A CtIDH somente julga casos contra Estados que aceitaram a sua jurisdição, como é o caso do Chile que aceitou a jurisdição contenciosa da Corte em 1990 (OEA, 2015).

${ }^{5}$ No início do seu funcionamento em 1960 a Comissão interpretou sua autoridade e iniciou uma atuação recepcionando denúncias de familiares e emitindo recomendações aos Estados. Em 1965 alcançou a expansão de suas funções por meio da Resolução XXII da OEA. Os Estatutos da Comissão e da Corte foram estabelecidos e sofreram alterações com o tempo, inclusive para permitir o encaminhamento de casos não solucionados pela CIDH à CtIDH para julgamento. Sobre a história e características estruturais do SIDH, vale conferir Goldman 2009.
} 
Latina (ABRAMOVICH, 2009; ACOSTA; ALVAREZ, 2011; ALMEIDA; TORELLY, 2010; BASCH et al, 2010; SCHONTEINER; COUSO, 2015; MICUS, 2015).

De acordo com Dykmann (2007), a década de 1970 registrou um período de atuação relevante da Comissão, haja vista que, de forma corajosa, tornou públicas as violações de direitos humanos dos regimes autoritários da América Latina. Também não se furtou de se manifestar sobre denúncias contra a potência regional em violações de direitos vinculadas as intervenções armadas dos Estados Unidos nos países do continente (MAIA; MACIEL; KOERNER, 2017).

Mesmo com os problemas de credibilidade enfrentados pela Comissão nos anos 1980 - especialmente em razão da imagem da OEA como instrumento da potência regional - o mecanismo trouxe importantes contribuições para a normativa dos direitos humanos.

Por sua vez, no transcorrer da década de 1990, o Sistema toma para si a função de monitorar os processos de transição dos países que passavam por mudanças no regime político. Dentre suas ações, estão as abertas críticas às leis de anistia, como a feita em 1989 pelo então presidente da CIDH Oliver Jackman, o qual designou estas leis como mecanismos de esquecimento e incompatíveis com a Convenção Americana. Posicionamento que foi reforçado com as sentenças emitidas pela CtIDH nas décadas seguintes (DYKMANN, 2007).

Em vista disso, fatos como o desmantelamento dos regimes autoritários, o fim da Guerra Fria e a maior capacidade dos ativistas de direitos humanos em se mobilizarem podem ser interpretados como características que contribuíram para que, no final do século XX, o SIDH fosse capaz de aproveitar oportunidades estratégicas para agir, de forma mais contundente, em prol da garantia dos direitos à memória, à verdade e à justiça.

Nesse sentido, a abertura do mecanismo regional de direitos humanos às demandas de ativistas, estabeleceu novos canais para a expressão de reivindicações de grupos sociais. Observa-se, portanto, a coordenação entre variados atores com características distintas, os quais tinham como intuito a promoção dos direitos à memória, à verdade e à justiça, apesar de suas divergências ideológicas. Posto isso, a próxima seção se debruçará sobre algumas 
das características do processo de justiça de transição na América Latina, as quais foram aproveitadas pelos atores a fim de promoverem suas demandas.

\section{O Processo de Justiça de Transição latino-americano: características gerais e a mobilização em torno dos direitos à memória, à verdade e à justiça}

O processo de justiça de transição contemporâneo, segundo Teitel (2003), teve seu início no pós-Segunda Guerra Mundial e é um conceito que remete a diferentes mecanismos, a depender da época em que se observa sua efetivação. Nesse sentido, a autora o compreende como processos de transformação política de sociedades saídas de momentos autoritários e conflituosos.

A partir de uma análise histórica, Teitel (2003) divide a evolução da justiça transicional em três fases diferentes. A primeira seria caracterizada pela responsabilização dos perpetradores de violações aos direitos humanos, em que a necessidade dessa medida não foi contestada. Já na segunda fase, é apresentada a relação entre punição e anistia, em que a escolha deveria ser feita entre uma delas, diante de um contexto em que a reconciliação nacional era necessária, dado o fim dos governos autoritários e repressivos. Por sua vez, a última das etapas é caracterizada como um movimento de criação de normativas e jurisprudências internacionais, que visam sustentar o processo de justiça de transição no interior dos Estados, de forma que se apresenta como uma fusão das fases anteriores.

Vale notar que não só os processos necessários durante as transformações políticas se alteram, como os atores que propiciam as modificações também variam. Nesse sentido, enquanto na primeira fase o centro está no Estado e em suas ações, na segunda o foco passa a ser a atuação de organismos da sociedade civil - dentre eles Organizações não governamentais (ONGs), organizações religiosas, grupos de direitos humanos, entre outros - os quais atuam na tentativa de arrefecer e solucionar conflitos (TEITEL, 2003).

Nesse sentido, os mecanismos para alcançar a reconciliação nacional envolvem métodos judiciais e políticos. Sendo assim, Almeida e Torelly os apresentam como quatro etapas distintas: restruturações institucionais e 
administrativas; políticas de reconciliação, esquecimento e memória; reparações às vítimas das violações; e transformação do sistema judicial para um que efetue o processamento criminal das violações (ALMEIDA; TORELLY, 2010, p. 42).

Tendo como propósito revelar os crimes praticados, punir os violadores, reparar às vítimas, reformar as instituições que promoveram abusos e fomentar a reconciliação entre as partes, as ações vinculadas ao processo transicional podem ser efetivadas por meio de diferentes mecanismos. Entre eles estão os tribunais internacionais, as leis de anistia, as ações penais e o estabelecimento das Comissões Nacionais da Verdade. (VAN ZYL, 2011, p. 47)

Depreende-se dessas análises, que a queda dos regimes autoritários na América Latina, no final do século $X X$, coloca o início do processo de justiça de transição latino-americano inserido na segunda fase acima descrita. Isto é, em um momento no qual é notória a tentativa dos governos da região em adotar medidas que buscassem a paz e a reconciliação nacional entre os grupos hostis, por meio de mecanismos predominantemente nacionais.

De acordo com Salmón (2011), é possível observar na América Latina a tendência de criação de leis de anistia e de Comissões da Verdade como formas de justiça de transição. Com efeito, o primeiro mecanismo adotado foi a criação de leis de anistia. No entanto, na maior parte das vezes, essas leis foram interpretadas de forma distorcida e utilizadas para isentar de culpa os agentes dos Estados envolvidos em crimes contra os direitos humanos. Por conseguinte, ao invés de promoverem a reconciliação nacional, garantiram a impunidade de perpetradores de crimes contra a humanidade ${ }^{6}$.

O acionamento do Sistema Interamericano de Direitos Humanos também foi uma prática comum, diante de um contexto que presenciou numerosas violações aos direitos humanos e que demandou a busca pela verdade e justiça. Nesta conjuntura, o SIDH foi receptor de um conjunto de petições de indivíduos e organizações não governamentais, que denunciavam transgressões vinculadas ao

\footnotetext{
${ }^{6}$ A Secretaria Nacional de Justiça, a Comissão de Anistia e a CtIDH lançaram, em 2014, o livro 'Jurisprudência da Corte Interamericana de Direitos Humanos: Direito à vida, anistias e direito à verdade', no qual jurisprudências de casos de Honduras, Peru, Chile, Brasil, Uruguai, El Salvador e Guatemala são apontadas como paradigmáticas. Nelas é possível observar os obstáculos que as leis de anistia trouxeram para o movimento de defesa do direito à memória, verdade e justiça.
} 
direito à memória, verdade e justiça. Segundo o informe de 2014 da CIDH - sobre o direito à verdade nas Américas - a litigância transnacional, neste campo, objetivou uma resposta frente à falta de esclarecimento, investigação, julgamento e sanção dos casos graves de violações aos direitos humanos por parte dos Estados (CIDH, 2014).

As solicitações junto ao SIDH promoveram não apenas a exposição dos Estados em suas práticas violadoras de direitos, mas também possibilitaram a própria construção do regime de direitos humanos na região, o qual foi marcado pela ampla discussão sobre o marco jurídico do direito à verdade como um pilar da justiça de transição.

As principais decisões do Sistema Interamericano sobre o tema afirmam: (1) o direito à verdade como resposta ao fenômeno do desaparecimento forçado; (2) o direito à verdade como elemento do direito à garantia e à proteção judicial; (3) o direito à verdade como medida de reparação; (3) a incompatibilidade das leis de anistia em relação às violações graves de direitos humanos; (4) a incompatibilidade e ilegitimidade da jurisdição militar em casos de violação graves dos direitos humanos; e (5) o direito de acesso à informação (CIDH, 2014).

Além do mais, o informe da CIDH (2014) destaca dentre as principais medidas nacionais para a adoção das obrigações derivadas do direito à verdade, a criação de Comissões Nacionais da Verdade, medidas judiciais para a responsabilização dos criminosos e medidas complementares de reparação e não repetição, tais como medidas legislativas; políticas públicas; desculpas públicas de autoridades dos Estados; e construção de museus, memoriais, arquivos e monumentos dedicados a recordar as violações.

No trecho abaixo é possível observar o reconhecimento por parte da CIDH do papel das redes de advocacy, no processo descrito:

Por um lado, cabe ressaltar a incansável atividade de vítimas, familiares, defensores e defensoras de direitos humanos e organizações da sociedade civil que têm reclamado e continuam reclamando para a obtenção da verdade, justiça e reparação em casos de violação dos direitos humanos. Ademais das iniciativas para levar a cabo e apoiar a investigação dos feitos, as vítimas e seus representantes, os defensores e defensoras de direitos humanos e as organizações da sociedade civil têm desempenhado um papel crucial no impulso e apoio para as reformas na legislação, na política 
e práticas necessárias para superar os obstáculos em relação ao direito à verdade [Tradução livre] (CIDH, 2014, p.12).

Destarte, é possível observar o engajamento das redes de advocacy em clara colaboração com atores da sociedade civil na busca pelo direitos à verdade, à memória e à justiça. Esse movimento presente nos anos da ditadura, também esteve presente durante o processo de redemocratização. Em um período onde os canais nacionais para a solução das violações de direitos humanos estavam obstruídos, a litigância internacional permitiu ampliar as demandas dos atores nacionais, forçando uma abertura ao debate de certas questões e visando o retorno dessas demandas ao ambiente interno (RISSE, SIKKINK, 1999). Em relação a isso, Abramovich afirma:

[...] foram essas organizações sociais que incorporaram com maior frequência os standards jurídicos fixados pelo SIDH como parâmetro para avaliar e fiscalizar ações e políticas dos Estados e, em algumas ocasiões, para impugná-las perante os tribunais nacionais ou ante a opinião pública local e internacional. (ABRAMOVICH, 2009, p. 14)

O caso do Chile torna-se ainda mais emblemático uma vez que o golpe de 1973 é considerado como um evento crucial na história do ativismo transnacional de direitos humanos ${ }^{7}$ (KELLY, 2013). Segundo Kelly (2013), o período foi marcado pela atuação de entidades de direitos humanos - dentre elas, a Anistia Internacional ${ }^{8}$ que desenvolveu na década de 1970 uma presença mais global - e de ativistas solidários, grupos de exiliados e esquerdistas que atuaram contra as ações abusivas dos governos autoritários. Todos os grupos, apesar de apresentarem visões rivais, adotaram o discurso transnacional dos direitos humanos no seu repertório de ação política.

É interessante observar, inclusive, que os primeiros anos da ditadura do General Pinochet impediram a organização da sociedade civil - à época a igreja era a única organização permitida. Assim, grupos cristãos formados por organizações

\footnotetext{
${ }^{7}$ Segundo Kelly (2013), o Chile obteve atenção global na década de 1970 uma vez que a eleição de Allende apontava para uma transição democrática para o socialismo. $O$ golpe promoveu a cooperação entre organizações não governamentais e até a atuação de Estados que passaram a mobilizar outras instâncias, inclusive a Comissão Interamericana de Direitos Humanos, na exposição das violações de direitos humanos ocorridas no país.

${ }^{8} \mathrm{Na}$ década de 1970 , o relatório da Anistia Internacional sobre o Chile foi a primeira tentativa formal de alertar a comunidade internacional sobre a situação de massivas violação de direitos no país. 0 relatório trouxe depoimentos de exilados e refugiados, o que conferiu credibilidade ao documento (KELLY, 2013).
} 
ecumênicas foram criados e atuaram não apenas no campo das campanhas de combate a crimes contra os direitos humanos, mas também registrando violações, a exemplo do Comitê de Cooperação para a Paz e da Comissão Chilena de Direitos Humanos ${ }^{9}$.

Como apontam Keck e Sikkink (1998) durante as décadas de 1970 e 1980 as organizações domésticas de direitos humanos apareceram de forma mais acentuada por toda a América Latina, e o país que liderou esse movimento foi o Chile. Além do mais, nota-se que algumas dessas organizações passaram a adotar como estratégia a mobilização para o acionamento de organizações internacionais, como o SIDH. Por conseguinte, a característica quase judicial da Comissão Interamericana de Direitos Humanos permitiu que a litigância internacional se tornasse um mecanismo dessa entidade.

Em vista disso, as próximas seções deste trabalho terão a função de demonstrar o contexto doméstico no Chile, o qual repercutiu globalmente e propiciou uma mobilização transnacional em torno da situação visualizada no país. Além de destacar o processo de litigância transnacional promovido contra o Chile no âmbito do Sistema Interamericano de Direitos Humanos.

\section{Do período ditatorial à transição para a democracia: as dificuldades de se alcançar a justiça transicional no Chile}

No dia 11 de setembro de 1973 ocorreu no Chile um golpe militar que levou ao poder as Forças Armadas e as de Ordem, as quais governariam o país por dezessete anos. Essas entidades compuseram a Junta de Governo que de início assumiu tanto o Poder Executivo, quanto o Legislativo e o Constituinte, ao mesmo tempo em que o Poder Judiciário, aparentemente, era salvaguardado da interferência do novo governo (CHILE, 1996a).

\footnotetext{
${ }^{9}$ O Comitê de Cooperação para a Paz era composto por diversas igrejas cristãs, e tinha como objetivo o registro das massivas violações de direitos humanos. Já a Comissão Chilena de Direitos Humanos foi criada em 1978 e publicava informes mensais sobre as violações de direitos humanos no Chile. Os responsáveis pela organização foram exilados do país no período. Ademias, o Comitê foi dissolvido em 1975, em razão da pressão governamental. Contudo, no ano seguinte foi criado o Vicariato da solidariedade que atuou por meio de alianças com outras organizações no ativismo contra as violações de direitos humanos vistas no período.
} 
Diante desse quadro, a Junta Militar alegou que o país passava por uma situação interna instável, na qual era perceptível a atuação de forças rebeldes e, assim, foi decretado estado de sítio - válido por toda a extensão do país - e estado de emergência, em algumas províncias e departamentos do Chile. Com isso, as garantias individuais dos cidadãos foram suspensas por tempo indeterminado. Essa situação seria postergada por um longo período, sendo o estado de exceção sustentado por quinze anos, enquanto o estado de sítio persistiria até 1978 também implementado outras vezes durante a década de 1980 (CHILE, 2004).

Ante à guerra interna alegada pelos militares, foram adotadas medidas que acabaram por promover massivas violações de direitos humanos. Nesse contexto, observa-se a censura dos meios de comunicação, bem como detenções arbitrárias, desaparecimentos forçados, execuções sumárias, exílio, tortura, entre outros abusos (ZALAQUETT, 2006, p. 27).

Logo após a efetivação do golpe militar, iniciou-se no país uma perseguição promovida pelos serviços de segurança às pessoas ligadas aos partidos políticos ${ }^{10}$, sindicatos e movimentos sociais. Muitas delas foram detidas, torturadas, executadas, exiladas ou desaparecidas - violências que foram direcionadas, principalmente, aos integrantes do Movimento da Esquerda Revolucionária (MIR), do Partido Socialista (PS) e do Partido Comunista (PC).

A repressão realizada no período de 1974 a 1977 foi intensa, as ações praticadas à época tinham como objetivo a eliminação de grupos considerados altamente perigosos, no que se referia às questões políticas. Assim, o ano de 1977 foi marcado por pressões externas, que fizeram com que o Estado dissolvesse um de seus principais braços de ação, a Direção de Inteligência Nacional (DINA). Este órgão era responsável pelo recolhimento de informações e criação de planos de ação considerados fundamentais para salvaguardar a segurança nacional do país, além de ter sido a entidade responsável pela repressão dos considerados inimigos políticos (CHILE, 1996b).

${ }^{10}$ O Informe Final da Comissão Nacional da Verdade e Reconciliação cita as várias resoluções emitidas pela Assembleia Geral da OEA, sobre a preocupação com a situação dos direitos humanos no Chile. Em 1981, as pressões dos órgãos do SIDH fizeram com que o Chile rompesse suas relações com a CIDH. Contudo, a CIDH continuou com as análises de casos e publicações de informes sobre o país (CHILE, 1996b, Tomo 2, p. 1128). 
Entretanto, mesmo com a extinção da DINA, as ações de investigação e contenção das insurgências continuaram com a criação da Central Nacional de Informações (CNI), cujo foco esteve até o ano de 1980, especialmente, nas questões relacionadas a inteligência (CHILE, 1996b).

Já no período final da ditadura militar, década de 1980, a CNI teve um importante papel no combate aos grupos insurgentes - dentre eles, o MIR e o grupo Mapu Lautaro -, os quais se fortaleceram nessa época. Diante dessa conjuntura, observou-se o uso excessivo da força por parte das autoridades estatais na contenção de manifestações públicas, resultando em várias mortes (CHILE, 1996b).

A transição política do país à democracia pôde ser caracterizada em sua primeira fase por medidas autoritárias, como a permanência de Pinochet como comandante chefe do exército, a auto-anistia de 1978, a Constituição de 1980 e o sistema eleitoral binominal, o qual garantia a representação da extrema direita no poder Legislativo.

Não obstante, diante das pressões internas e internacionais sofridas pelo governo chileno, foi realizado no país, no ano de 1988, um plebiscito que tinha como intuito questionar a continuidade do governo vigente. Diante da negação, por parte da população, sobre a continuidade do regime, foram realizadas no ano seguinte eleições presidenciais que tiveram como vencedor Patricio Aylwin. Em março de 1990 o novo presidente assume o cargo, momento em que tem início o processo de redemocratização chileno (ZALAQUETT, 2006).

Apesar de Aylwin ter implementado algumas medidas que favoreceram a justiça de transição ${ }^{11}$, esse processo não foi isento de obstáculos. Pelo contrário, a herança do regime autoritário ainda se manteve presente, a partir de um Congresso Nacional ainda muito travado, o que impossibilitou, nos primeiros anos após a mudança de regime, a concretização de reformas institucionais. Sobre os limites democráticos, Wilde aponta:

\footnotetext{
${ }^{11}$ Vale ressaltar que no Informe de 1989-1990, a CIDH aponta a melhoria na situação dos direitos humanos no país, ocorrida desde a realização do plebiscito em outubro de 1988. Meses depois da posse do novo presidente chileno, o país ratificou no dia 10 de agosto de 1990 a Convenção Americana de Direitos Humanos, a qual tinha sido assinada em 22 de novembro de 1969 - a aceitação da competência da Corte se deu no dia 21 de agosto de 1990 (CIDH, 1990).
} 
Em outros níveis, a democracia ficou limitada por valores e mentalidades autoritários incorporados em atores políticos, organizações e setores sociais influentes, cuja adesão à prática democrática era, no melhor dos casos, limitada. Estes atores, sobretudo, as Forças Armadas e o Poder Judiciário [...], exerceram um importante poder de fato para manter a conspiração de consenso [Tradução livre] (WILDE, 2007, p. 13).

É notório que nos anos iniciais da transição política havia uma limitação na capacidade do Executivo de adotar medidas que promovessem a reparação das violações, bem como reformas que possibilitassem a não repetição de casos semelhantes. O forte papel dos militares no processo de transição garantiu, inclusive, restrições legais e constitucionais (SKAAR, 1994). Além da ausência de consenso entre os três poderes, era possível observar a formação de alianças contrárias à agenda de reformas, fator que gerou impactos negativos para a política de direitos humanos (COLLINS, 2009).

A Corte Suprema também se alinhou à posição de contrariedade às reformas propostas, uma vez que temia a limitação de seu poderio. Como consequência, visualiza-se no período a ampliação no encaminhamento de petições ao $\mathrm{SIDH}$, as quais solicitavam mudanças legislativas e no poder judiciário. Uma das denúncias enviadas nesse ínterim foi o Almonacid versus Chile, que ao questionar a lei de anistia como forma de isentar crimes contra a humanidade ${ }^{12}$ se tornou um caso paradigmático.

Em vista disso, a implantação de reformas constitucionais e a execução de julgamentos sobre as violações de direitos humanos se desenvolveram de forma tardia no país. Como aponta Wilde (2007) a mobilização em torno dessas questões foi determinante para as mudanças institucionais. Com isso em mente, a próxima seção terá a incumbência de analisar a mobilização chilena, a qual repercutiu tanto

\footnotetext{
${ }^{12} \mathrm{Em} 15$ de setembro de 1998, frente à decisão da Suprema Corte chilena que garantia a impunidade para perpetradores de crimes contra a humanidade durante o período da ditadura militar, Mario Máquez Maldonado e Gómez Olivares ingressaram com a petição 12.057 ante a CIDH. O caso foi processado pela Comissão, a qual encaminhou o caso à CtIDH diante da posição chilena que permitia a impunidade de tais crimes. No caso julgado pela Corte IDH "Almonacid Vs. Chile" de 2006, o Estado do Chile admitiu que a lei de anistia era contrária às normativas de direitos humanos e afirmou que tinha sido criada durante o governo ditatorial com o objetivo de evitar a responsabilização dos agentes do governo pelas violações dos direitos humanos. Nesse sentido, o Estado reconheceu que a responsabilidade do governo em relação à existência da lei de anistia se mantinha, de forma que o Estado do Chile continuava violando a Convenção Americana de Direitos Humanos (COLLINS et al, 2013).
} 
na promoção do direito à verdade e à justiça, como na implementação de medidas que modificaram a estrutura do Estado chileno.

\section{5. $O$ ativismo chileno no Sistema Interamericano de Direitos Humanos em prol} da verdade e da justiça

Com o intuito de analisar o perfil das denúncias enviadas contra o Estado chileno ao $\mathrm{SIDH}$, com foco para as denúncias que visam garantir o direito à verdade e à justiça, serão utilizadas as informações coletadas na base de dados, do NUPEDH-IERIUFU, sobre o Sistema Interamericano de Direitos Humanos em relação aos casos de violações aos direitos humanos submetidas contra os Estados sul-americanos.

A base de dados é composta por informações retiradas dos relatórios de mérito, admissibilidade, inadmissibilidade e arquivamento disponíveis no sítio oficial da $\mathrm{CIDH}$, assim como das sentenças emitidas pela $\mathrm{CtIDH}$ igualmente disponibilizadas no seu site oficial. No banco de dados são destacadas informações como: tipo principal da violação alegada, andamento do processo nos referidos órgãos, características das vítimas, detalhes dos denunciantes, tipo de atuação dos peticionários, normativas mobilizadas nas denúncias, pronunciamento dos órgãos do Sistema e respostas dos Estados.

A partir disso, é possível observar que a primeira denúncia enviada contra o Chile foi recebida pela CIDH no ano de 1973. Deste ano até 2017, a Comissão Interamericana registrou 109 casos de violação aos direitos humanos contra 0 Estado chileno, dos quais 97 foram admitidos, 8 foram inadmitidos e 4 arquivados. Dos 93 casos admitidos, 53 deles já tiveram decisões de mérito e 8 foram enviados à Corte IDH.

A maior parte das denúncias existentes contra o país está concentrada entre as décadas de 1990 e 2000, o que representa 70 dos 109 casos recepcionados pela CIDH. De 1970 à 2017, a distribuição das denúncias no tempo é caracterizada da seguinte forma: década de 1970, 32 casos ; década de 1980, 6 casos; 22 casos na 
década de 1990; e a partir do ano 2000, $48 \operatorname{casos}^{13}$ - em apenas 1 denúncia não foi possível identificar a data de envio da petição. Em relação aos temas de denúncia de todos os casos referentes ao Chile, o gráfico 1 apresenta sua distribuição.

\section{Gráfico 1: Temas de denúncias submetidas contra o Estado do Chile}

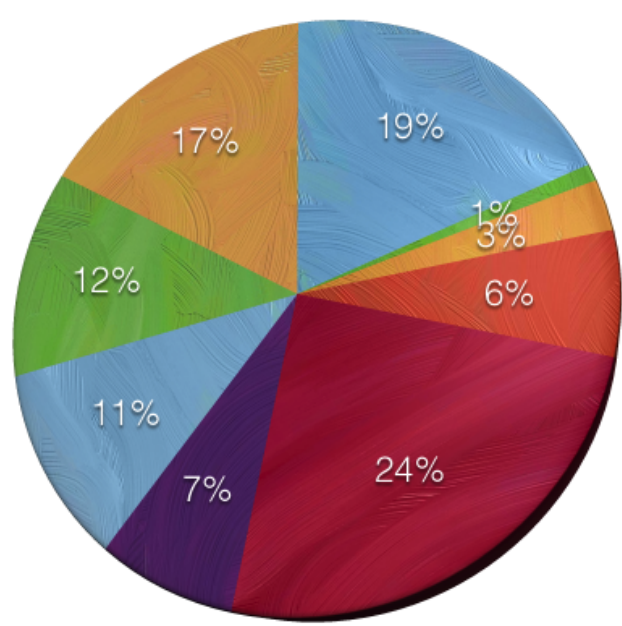

Detenção arbitrária

Execução

Migração, refugiados e apátridas

Violação do devido processo legal

Outros
Desaparecimento forçado

Discriminação

Violação da liberdade de expressão

Violação dos direitos e garantias legais

Fonte: Elaboração própria a partir dos dados de MAIA, M. e GARBIN, I. Base de Dados sobre os Casos do SIDH, 2018.

No que diz respeito aos temas das denúncias é possível observar que os casos se relacionam, em sua grande maioria, aos temas associados a: migração, refugiados e apátridas (24\%); detenção arbitrária (19\%) e violação dos direitos e garantias legais (12\%). Referente ao período específico de justiça de transição os temas mais denunciados podem ser observados no próximo gráfico.

13 Como a década de 2010 ainda não está completa, agrupamos os dados nos anos 2000. 


\section{Gráfico 2: Temas de denúncias referentes à justiça de transição}

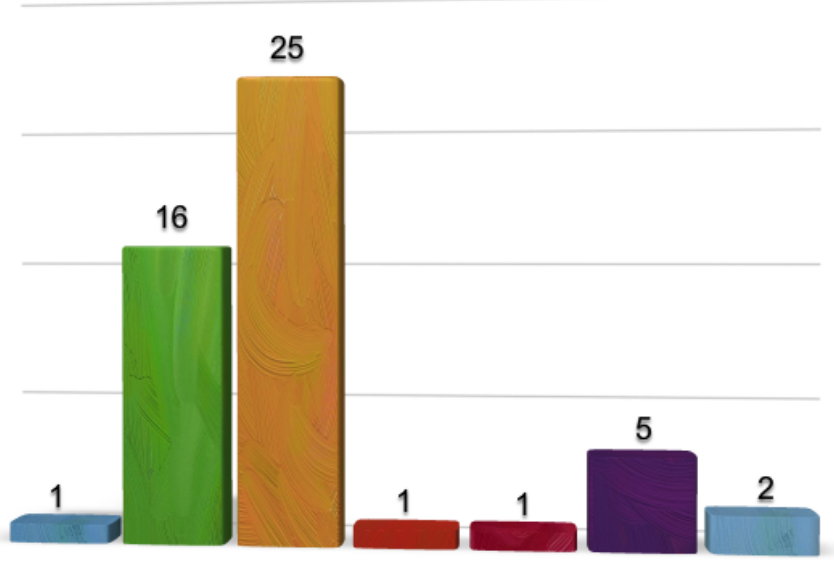

Desaparecimento forçado

Migração, refugiados e apátridas

Violação do devido processo legal Outros
Detenção arbitrária

Execução

Violação dos direitos e garantias legais

No que tange às denúncias relacionadas aos temas de justiça de transição, 51 petições foram analisadas pelo SIDH. Destas, a temática mais denunciada é migração, refugiados e apátridas, as quais se relacionam com casos sobre exílio ocorridos durante os anos de 1973 à 1990. Em relação a isso Lira e Loveman (2005, p. 242) demonstram que o informe da CIDH - sobre a situação dos direitos humanos no Chile de 1985 - apontou numerosas violações ao direito de ir e vir, haja vista que o governo passou a negar por motivações políticas o "direito do nacional de viver em sua pátria”.

Detenção arbitrária e violação dos direitos e garantias judiciais também foram temáticas presentes nas denúncias referentes ao período ditatorial. Por sua vez, violações relacionadas ao devido processo legal, liberdade de expressão, propriedade privada e omissão dos serviços administrativos por parte do governo são temas que se tornaram mais recorrentes após o processo de redemocratização do país. 
Grande parte das denúncias encaminhadas ao Sistema Interamericano, cujas violações ocorreram durante à ditadura militar omitem os nomes dos peticionários - em 37 casos os nomes dos denunciantes são mantidos em sigilo. Em relação às outras 14 denúncias relativas ao período, 10 foram encaminhadas por civis, 2 por organizações e 2 por civis e organizações em conjunto.

O sigilo em relação aos denunciantes, a princípio, dificultaria uma análise sobre o perfil de atuação e mobilização do ativismo jurídico de direitos humanos em relação ao Chile, no que tange aos casos sobre justiça de transição. Bem como impediria a identificação das redes de advocacy atuantes à época. No entanto, o Anuário Interamericano de Direitos Humanos de 1987, organizado e publicado pela $\mathrm{CIDH}$, traz informações reveladoras sobre a mobilização no período.

Nesse sentido, o documento destaca a preocupação da Comissão com as medidas das autoridades governamentais contra os organismos defensores dos direitos humanos, especialmente em relação a algumas organizações não governamentais que atuavam no país. Inclusive, cita os Informes de 1983 e 1984 com o intuito de reforçar a recomendação de "máximo de prudência e ponderação com os organismos defensores de direitos humanos e com as instituições cujas atividades tem conteúdo humanitário" (CIDH, 1987, p. 995).

A publicação ainda descreve a perseguição do Estado chileno ao Comitê de Cooperação para a Paz, criado em 1973 e constituído por organizações religiosas, com o objetivo de promover a ajuda humanitária, assim como denunciar as violações dos direitos humanos ocorridas no período ${ }^{14}$. O líder do departamento jurídico, José Zalaquet, foi exilado à época exatamente pelas atividades de combate aos crimes contra os direitos humanos. Zaquelet acabou por atuar posteriormente à frente da ONG Anistia Internacional e, após a redemocratização do país, foi escolhido para compor a Comissão Nacional da Verdade e Reconciliação do Chile (CNVR).

Outra organização não governamental também importante no período, foi a Comissão Chilena de Direitos Humanos. Criada em 10 de dezembro de 1978, passou a publicar relatórios mensais sobre a situação dos direitos humanos no

\footnotetext{
${ }^{14} \mathrm{O}$ Anuário apresenta a cópia da carta escrita por Pinochet e encaminhada para o Comitê, na qual solicitava o fim das atividades do organismo, haja vista que suas atividades eram interpretadas como de caráter político.
} 
Chile. Seu dirigente, Jaime Castilho, também foi exilado do país e, segundo o Anuário da Comissão (1987), juntamente com Eugênio Velasco forneceram informações relevantes para a atuação da CIDH. Jaime Castillo, ainda como presidente da organização Comissão Chilena de Direitos Humanos, foi membro da Comissão Nacional da Verdade e Reconciliação do Chile.

Nota-se, portanto, que a mobilização que provocou a denúncia da situação dos direitos humanos no Chile se constitui logo após o golpe de Estado de 1973, como uma reação à brutalidade adotada pelas forças do regime que tinham o objetivo de eliminar quaisquer tipo de apoio ao governo socialista que acabara de ser destituído ou oposição ao novo governo. Esta postura adotada por Pinochet gerou uma grande repercussão internacional e fez com que ONGs, organismos internacionais e grupos de esquerda direcionassem suas atenções à crítica situação dos direitos humanos no Chile. Com a instauração do novo regime, uma grande massa de chilenos foi exilada do país e se instalou em diversos Estados ao redor do mundo (KELLY, 2013).

A repercussão causada pela brutalidade do governo de Pinochet e o grande número de exilados, os quais presenciaram e muitas vezes foram vítimas das violações, contribuíram para que no exterior essas pessoas se unissem e dessem origem a uma rede de indivíduos e organizações, que tinham como finalidade denunciar as violações de direitos humanos que estavam ocorrendo no país. Desse modo, o processo de denúncia à situação existente no Estado chileno se fortaleceu, a partir da criação de um movimento transnacional de solidariedade que contou com o apoio de organizações cristãs, grupos socialistas e ONGs internacionais - entre elas a Anistia Internacional, a Comissão Internacional de Juristas e o Comitê Internacional da Cruz Vermelha. Como consequência, de acordo com Kelly (2013), o golpe ocorrido no Chile contribuiu para criar e aumentar a consciência das pessoas a respeito dos direitos humanos em todo o mundo.

Por essa razão, o movimento de solidariedade além de dispor da colaboração de organizações e de pessoas diretamente relacionadas e afetadas com o que estava ocorrendo no país - como os exilados, estudantes e associações sindicais chilenas -, também teve a participação de variados grupos e pessoas que 
muitas vezes possuíam interesses e visões políticas distintas, mas que diante das circunstâncias se juntaram para denunciar as atrocidades cometidas pelo regime de Pinochet (ELSEY, 2013).

De forma similar, os organismos internacionais também fizeram parte dessa rede e foram impelidos por ela. A CIDH foi uma das agências internacionais provocadas a atuar diante do Relatório emitido pela Anistia Internacional em 1973, o qual ressaltava a péssima condição dos direitos humanos visualizada no país. A visita feita pela Anistia Internacional no mesmo ano do golpe de Estado precedeu a observação in loco efetuada pela Comissão Interamericana em 1974. Contudo, muitos dos lugares em que a Anistia foi impedida de visitar, em decorrência de seu caráter de organização não governamental, a CIDH conseguiu acesso e constatou a degradante situação dos direitos humanos existente. Como consequência disso, foi elaborado o relatórios mais crítico realizado pela Comissão Interamericana até aquele momento (ENSALACO, 2000).

Todavia, seria durante os anos de 1990, momento em que a região da América Latina era caracterizada pela abertura política nos países autoritários e pela implementação dos processos de redemocratização, que as redes de advocacy se tornariam mais atuantes. Não obstante, a mobilização transnacional em torno do caso chileno se iniciou no mesmo ano do golpe militar e foi impulsionada pela massa de chilenos que foi expulsa do país e se instalou em outras regiões, a partir das quais continuou atuando contra o regime de Pinochet.

Nesse sentido, a mobilização chilena foi a percursora no continente americano, uma vez que apesar da ditadura militar chilena não ter sido a primeira a ser instaurada na região, foi a primeira que conseguiu atrair, de forma significativa, as atenções da comunidade internacional. Como consequência da imediata atuação dos ativistas em relação ao Chile, dos 51 casos processados pela Comissão sobre os casos relativos ao período militar, a maioria das petições foi enviada ainda durante os anos 1970, como demonstra o gráfico 3. 


\section{Gráfico 3: Petições enviadas contra o Chile sobre Justiça de Transição, separadas por décadas}

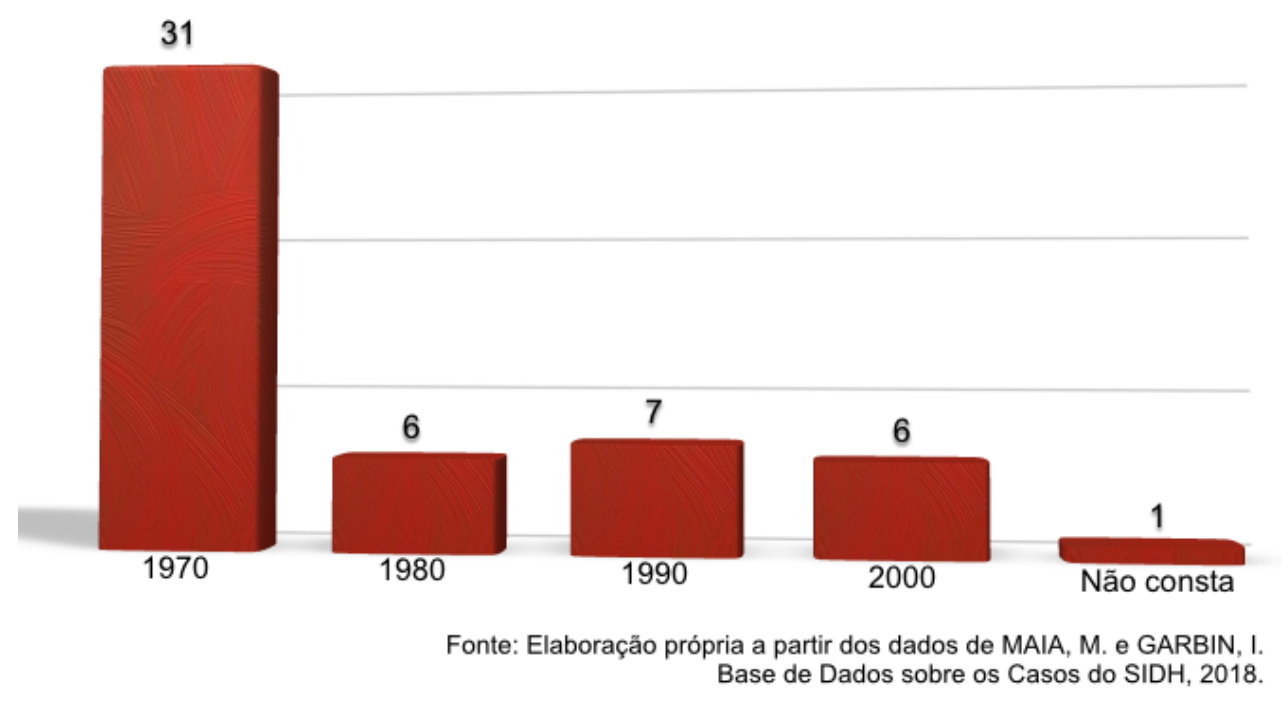

Entretanto, vale dizer que a mobilização chilena não repercutiu somente no sistema de peticionamento do Sistema Interamericano de Direitos Humanos. A atuação da CIDH durante as décadas de 1970 e 1980 se deu, principalmente, a partir da execução de visitas in loco e da elaboração de informes, haja vista que diante de situações generalizadas de violações aos direitos humanos, a Comissão optou por adotar uma estratégia que lidasse de uma forma mais holística com a circunstância existente, ao invés de tratar casos individuais (LEBLANC, 1977; ENSALACO, 2000). Além do mais, como aponta Bernardi (2017), a CIDH priorizou o sistema de relatorias, uma vez que os regimes repressores não estavam dispostos a mudar suas práticas, assim como não reconheciam a legitimidade das denúncias e da própria Comissão Interamericana.

Portanto, constata-se que a atuação inaugural em torno do caso do Chile viabilizou a expansão da atividade das ONGs no final do século XX. Nota-se, por conseguinte, que algumas das organizações que atuaram como denunciantes a partir dos anos 1990, foram criadas, bem como trabalharam intensamente ainda no período da ditadura militar. Entre as com dimensão internacional estão a Anistia 
Internacional, a Human Rights Watch, o Centro pela Justiça e pelo Direito Internacional (CEJIL) e a Seeking Reparation for Torture Survivors (REDRESS). ONGs domésticas como a Corporación de Promoción e Defensa del Pueblo (CODEPU) e a Corporación de Desarollo de la Mujer também participaram de forma intensa no transcorrer dos anos autoritários.

Por outro lado, durante os anos 1990 vários organizações emergiram e se tornaram atuantes perante o SIDH, entre elas estão a ONG internacional Humanas e as ONGs domésticas Grupo Chileno de Objeción de Conciencia "Ni casco ni uniforme", Centro de Estudios Jurídicos Sociales y Documentación Indígena, Observatorio Ciudadano, Observatorio de Derechos de los Pueblos Indígenas e Movimiento de Integración y Liberación Homosexual. Vale também ressaltar a atuação da Clinica de Ações de Interesse Público da Universidade de Diego Portales. Destas, somente a Universidade atuou em casos cujo tema principal da denúncia estava vinculado ao processo de justiça transicional.

Para Abramovich (2009), o contexto de abertura política marcou a ampliação da atuação de ONGs locais no Sistema Interamericano de Direitos Humanos, mas também a formação de associações entre diversas organizações para a atuação em rede $^{15}$. Sendo assim, com o propósito de analisar a atuação em rede dos peticionários no SIDH, levantamos os casos onde pudemos observar coalizões no encaminhamento de denúncias, conforme tabela abaixo.

\footnotetext{
${ }^{15}$ Essa afirmação foi contestada por Collins (2009) em investigação que revelou uma desmobilização de parte das organizações como o Vicariato da Solidariedade que foi desativado em 1992 e suas atividades foram transferida para a CODEPU. Em seu estudo focado na mobilização em torno da responsabilização individual por crimes cometidos contra a ditadura militar, investigando 0 indiciamento de Pinochet em tribunais estrangeiros, demonstra que muitos dos ativistas envolvidos agiam a título pessoal. Para a autora, fatores internos como por exemplo, a pressão de atores nacionais, influenciaram mais as mudanças domésticas no ressurgimento da responsabilidade penal por violações de direitos humanos no período da ditadura do que o ativismo internacional. A autora também ressalta o fato de que muitas personalidades extremante atuantes no período da ditadura não foram as mesmas que protagonizaram o debate sobre accountability nos seus países. Não obstante, vale recordar outra observação da autora em que o Chile conta com pelo menos duas gerações de advogados de direitos humanos. A primeira geração estava vinculada principalmente ao Vicariato da Solidariedade. E a segunda geração, mais jovem e com perfil ideológico mais radical, que trabalha na CODEPU, organização que herdou os casos do Vicariato e que tem contribuído desde 1998 para patrocinar causas contra Pinochet e outras pessoas responsáveis pelas violações de direitos humanos durante a ditadura militar.
} 
Tabela 1: Atuação em rede nos casos chilenos processados pela Comissão Interamericana de Direitos Humanos

\begin{tabular}{|l|r|}
\hline Atuação em rede & Total de casos \\
\hline Não & \\
\hline Não se aplica & 39 \\
\hline Não se aplica (peticionários mantidos em sigilo) & 31 \\
\hline Sim & 38 \\
\hline Entre indivíduos & 40 \\
\hline Entre indivíduos e ONGs & 13 \\
\hline Entre ONGs & 11 \\
\hline Entre ONGs e Organizações Privadas & 6 \\
\hline Entre indivíduos e Organizações Privadas & 5 \\
\hline Entre indivíduos e diversas organizações & 2 \\
\hline Entre Organizações Privadas & 1 \\
\hline Total de casos & 109 \\
\hline
\end{tabular}

A partir dos dados da tabela, nota-se que em 69 dos 109 casos recepcionados pela CIDH não se pode observar a atuação em rede - é necessário lembrar que em 38 casos os nomes dos peticionários foram mantido em sigilo, de modo que somente em 31 casos a atuação em rede não se aplica de fato. Por conseguinte, a maior parte dos casos em que constam os peticionários, 0 encaminhamento ocorreu por meio da atuação em rede de indivíduos com a participação de ONGs ou somente entre indivíduos. Vale ainda ressaltar, que dos 40 casos em que se observa a atuação em rede, seis ocorreram antes da transição política, de modo que os 34 que restaram foram encaminhados pós-1990.

Sobre isso Keck e Sikkink (1998) afirmam que os ativistas nacionais privilegiam as oportunidades políticas domésticas, mas mantêm o ativismo internacional como opção e preservam esse caminho como estratégia de mobilização ${ }^{16}$. Isto porque - de acordo com o "modelo bumerangue" desenvolvido

${ }^{16}$ É importante lembrar, conforme o discutido anteriormente, que após a redemocratização ainda era possível observar resquícios do período autoritário, de forma que atores políticos, organizações e 
pelas autoras - as redes de ativistas domésticas ao verem suas demandas serem frustradas no âmbito nacional, recorrem a arena internacional em busca de aliados que as auxiliem a amplificar suas reinvindicações. Além do mais, a estratégia das coalizões promovem a circulação de informações sobre as violações de direitos humanos e aumentam os resultados da litigância.

Em vista disso, observa-se que as coalizões transnacionais ocorreram em temas como detenção arbitrária, violação da liberdade de expressão, violação do devido processo legal e violação dos direitos e garantias judiciais, entre outros. Vale ainda destacar a participação de ONGs por meio de manifestações públicas sobre os casos e como amicus curiae em denúncias analisados pela $\mathrm{CtIDH}^{17}$.

Como resultado da mobilização chilena em torno das ocorrências referentes à justiça de transição, 43 dos 45 casos que tiveram decisão de mérito dispõem de recomendações emitidas pela $\mathrm{CIDH}$. As principais orientações formuladas pelo organismo estão relacionadas ao direito à justiça e à verdade, de modo que a Comissão demandou ao Estado que ele cumprisse com os deveres de investigar e punir os culpados, reparasse moral e materialmente às vítimas das violações, bem como adequasse a legislação interna às normativas internacionais.

Com efeito, parte das recomendações da Comissão foram alcançadas, não como resultado de uma resposta do Estado ao mecanismo, mas como parte de um processo mais amplo de transformações do governo chileno após o fim do período autoritário. Nesse sentido, é possível identificar no marco dos diferentes governos que sucederam o regime militar, ações que respondem ao posicionamento da CIDH.

Um exemplo é o da criação e atuação da Comissão Nacional de Verdade e Reconciliação do Chile, cuja composição revela também a participação de

setores sociais agiam em conformidade com o legado autoritário. Desse modo, verifica-se que as violações dos direitos humanos relacionadas às forças policiais e armadas estão vinculadas com a herança deixada pelos conflitos do passado autoritário, e a partir da qual são justificadas (GRANDIN, 2007; WILDE; 2007). Nesse sentido, observam-se demandas no SIDH sobre violações de direitos humanos ocorridas já durante a democracia, mas que guardam fortes relações com práticas da ditadura, como a violência policial ou os maus tratos em prisões.

${ }^{17} \mathrm{~A}$ Associação Americana de Juristas, por exemplo, atuou no caso Almonacid vs Chile. 
importantes ativistas que lutaram contra a ditadura em redes transnacionais, inclusive como peticionários no SIDH $^{18}$ (KREFT; LE SAUX; LAUZÁN, 2011).

O resultado da atuação conjunta entre as redes de advocacy e o Sistema Interamericano de Direitos Humanos também pode ser visto no esforço da Comissão Nacional da Verdade e Reconciliação, bem como de outras políticas públicas adotadas pelo Chile. Estas visavam elucidar a verdade em relação aos casos de violações de direitos humanos ocorridas durante a ditatura militar, bem como conceder reparações às vítimas ou a seus familiares. Assim, entre os casos analisados pela CIDH e que posteriormente passaram pela averiguação da CNVR podem ser citados, entre outros, os casos Michel Salin Nash Sáez y otros, Juan Antonio Aguirre Ballestreros e Carmelo Soria Espinoza.

Entretanto, no campo da responsabilização individual por crimes cometidos durante a ditadura, as respostas foram escassas e vieram especialmente de juízes progressistas que passaram a interpretar o direito de forma a alcançar a accountability $^{19}$. Hau (2018), por exemplo, relata o primeiro caso que se fez justiça no Chile, frente ao tema de desaparecido político - a sentença proferida por Alejandro Solis, em 2004, estabeleceu a tese de sequestro permanente da vitima e condenou um ex-agentes da DINA responsável pelo crime.

No que tange a este assunto, observa-se que a Lei de Anistia de 1978 foi um grande obstáculo para a punição dos responsáveis dos crimes cometidos, assim como a relutância da Corte Suprema de lidar com os casos de violações denunciados. A estrutura hierárquica do poder judiciário também contribuiu para que instâncias inferiores à Corte Suprema não atuassem contrariando as orientações da instância máxima, que nos anos seguintes à redemocratização ainda era vista como leal ao regime de Pinochet e extremamente conservadora (SKAAR, 2011).

\footnotetext{
${ }^{18}$ Os membros da CNVR foram o Ex-Senador e Presidente do Colegio de Abogados, Raúl Retting; o Presidente da Comissão Chilena de Direitos Humanos, Jaime Castillo Velasco; o Professor Universitário Jose Luis Cea; a representante da Comisión de Paz y Justicia, Monica Jimenez; o ExMinistro da Suprema Corte, Ricardo Matin; a professora universitária Laura Navoa; o Ex-Ministro do Governo Militar, Gonzalo Vial; e o Ex-Presidente da Anistia Internacional, José Zaquett.

${ }^{19}$ Sobre isso, vale conferir o estudo de Bernardi (2015), o qual a partir de uma análise de casos sobre o Peru observa o grau de impacto do SIDH na judicialização de denúncias referentes à justiça de transição. $\mathrm{O}$ autor enfatiza o papel da sociedade civil e as respostas do Judiciário doméstico como canais abertos a influência do Sistema.
} 
A modificação dessa postura se deu, como argumenta Skaar (2011), com a prisão de Pinochet em Londres em 1998. Entre os anos de sua prisão e seu indiciamento e afirmação por parte da Corte Suprema de que Pinochet deveria ser julgado (2001), os tribunais internos receberam um enorme montante de denúncias referente à ditadura militar e visualizaram a reabertura de vários processos que estavam parados diante da resistência do tribunal em julgá-los. Desse modo, foi no transcorrer dos anos de 1998 e 2001 que vários casos foram julgados, o caso de Augusto Pinochet ${ }^{20}$ abriu um procedente para a condenação de outros perpetradores de violações de direitos humanos, ainda que a Lei de Anistia não tivesse sido revogada (SKAAR, 2011).

Em vista do exposto, observa-se que a advocacy transnacional em torno do caso chileno foi o primeiro movimento de mobilização com esse caráter na região da América Latina. O movimento iniciado já na década de 1970 viabilizou a maior atuação das redes de advocacy nos anos 1990, assim como pavimentou o caminho para que outros movimentos que buscassem garantir os direitos à memória, à justiça e à verdade, em relação às violações de direitos humanos perpetradas pelos regimes autoritários, prosperassem nos outros Estados do continente.

\section{Conclusão}

A análise sobre a mobilização em torno da justiça de transição em relação ao Chile aponta a importante interação entre organizações, indivíduos, redes de advocacy, instituições internacionais e Estado na promoção e efetivação de demandas sobre justiça, memória e reparação das violação de direitos humanos ocorridas durante as ditaduras militares na América Latina.

A mobilização transnacional que buscou denunciar as violações de direitos humanos cometidas pelo regime de Pinochet foi a primeira a ocorrer no continente americano e contou com a criação de um movimento internacional de solidariedade, bem como com a participação de ativistas em instituições internacionais tanto para

${ }^{20}$ Augusto Pinochet faleceu em 2006 quando ainda era julgado em dois processos, um por crimes relacionados a transações financeiras e outro por violações aos direitos humanos (SKAAR, 2011). 
difundir a péssima situação dos direitos humanos no país, como para buscar justiça e modificar a situação vigente.

O caso chileno ajudou a moldar a estratégia de mobilização internacional de ONGs domésticas e internacionais, as quais passaram a adotar novas formas de ativismo e advocacy por meio do envio de denúncias a órgãos internacionais e da emissão de relatórios críticos sobre a situação dos direitos humanos. Também transformou a relação entre os grupos da sociedade civil e o Sistema Interamericano de Direitos Humanos, o qual atuou não só recebendo diversas denúncias de violações, mas também acionando seus próprios mecanismos - a partir da emissão de relatórios, visitas in loco e sentenças da CtIDH - para processar o caso e gerar mudanças de comportamento do Estado.

Portanto, a estratégia de mobilização das redes de advocacy por meio da litigância internacional em relação ao caso do Chile fortaleceu a demanda para os casos individuais denunciados e promoveu mudanças legislativas, jurídicas e políticas. Do mesmo modo que serviu como uma referência para mobilizações futuras no Sistema Interamericano, que tiveram como princípio abordar o tema de justiça de transição.

Por fim, este artigo ainda aponta para a necessidade, não explorada neste trabalho, de estudar o Sistema Interamericano de Direitos Humanos como uma instância não monolítica, a qual teve suas decisões influenciadas por burocratas que se vincularam tanto à rede de solidariedade quanto à rede democrata cristã presente na América Latina e que promoveram os debates em torno do passado autoritário no Chile e da justiça de transição no âmbito das organizações internacionais, em especial da OEA.

\section{Referências}

ABRAMOVICH, Victor. Das violações em massa aos padrões estruturais: novos enfoques e clássicas tensões no Sistema Interamericano de Direitos Humanos. Sur: Revista Internacional de Direitos Humanos, v. 6, n. 11, p. 0739, 2009.

ACOSTA, Juana Ines; ALVAREZ, Lina. Logical Lines of Investigation: a contribution 
of the Inter-American System of Human Rights to the Prosecution of system crimes in transitional justice frameworks. International Law: Revista Colombiana de Derecho Internacional n. 18, p. 57-87, 2011.

ALMEIDA, Eneá de Stutz; TORELLY, Marcelo. Justiça de Transição, Estado de Direito e Democracia Constitucional: Estudo preliminar sobre o papel dos direitos decorrentes da transição política para a efetivação do estado democrático de direito. Sistema Penal \& Violência, v. 2, n. 2, p. 36-52, 2010.

BASCH, Fernando et al. The Effectiveness of the Inter-American System of Human Rights protection: A quantitative approach to its functioning and compliance with its decision. Sur: International Journal on Human Rights, v.7, n.12, p. 8-35, 2010.

BENFORD, Robert D.; SNOW, David A. Framing processes and social movements: An overview and assessment. Annual Review of Sociology, v. 26, n. 1, p. 611-639, 2000.

BERNARDI, Bruno Boti. O sistema interamericano de direitos humanos e a justiça de transição: impactos no Brasil, Colômbia, México e Peru. Tese de Doutorado em Ciência Política, Universidade de São Paulo, 2015.

. The case of the Araguaia guerrilla movement and the Inter-American Human Rights System: impacts on Brazil. Revista Brasileira de Ciência Política, n. 22, p. 49-92, 2017.

CARLETON, David; STOHL, Michael. The Role of Human Rights in U.S Foreign Assistance Policy: a Critique and Reappraisal. American Journal of Political Science, v. 31, n. 4 , p. $1002-1018,1987$.

CHILE. Comisión Nacional de Verdad y Reconciliación. Informe de la Comisión Nacional de Verdad y Reconciliación, v. 1, Tomo 1, 1996a.

. Comisión Nacional de Verdad y Reconciliación. Informe de la Comisión Nacional de Verdad y Reconciliación, v. 1, Tomo 2, 1996b.

. Comisión Nacional sobre Prisión Política y Tortura. Informe Comisión Nacional sobre Prisión Política y Tortura. Santiago, 2004.

COLLINS, Cath. Human rights trials in Chile during and after the 'Pinochet Years'. International Journal of Transitional Justice, v. 4, n. 1, p. 67-86, 2009.

COLLINS et al. Verdad, Justicia y Memoria por violaciones de derechos humanos en tempos de dictadura, a 40 años del Golpe Militar. 2013. Disponível em: < http://www.icso.cl/wp-content/uploads/2011/03/udp ddhh 2013 cap 01.pdf> Acessado em 05 de agosto de 2015.

COMISIÓN INTERAMERICANA DE DERECHOS HUMANOS (CIDH). Anuario Interamericano de Derechos Humanos. Boston: Martinus Nijhoff Publishers, 1987. 
Informe Anual (1989-1990). 1990. Disponível em: < http://www.cidh.org/annualrep/89.90span/indice.htm> Acessado em 23 de junho de 2016.

Derecho a la Verdad en las Americas. OEA/Ser.L/V/II.152, doc. 2, 13 de agosto de 2014. Disponível em < http://www.oas.org/es/cidh/informes/pdfs/derechoverdad-es.pdf $>$ Acessado em 23 de junho de 2015.

. Impunity and the right to truth in the inter-American system of human rights. Iberoamericana, v. 7, n. 26, p. 45-66, 2007.

ELSEY, Molly. "As the World is my witness": Transnational Chilean Solidarity and Popular Culture. In: MOR, Jessica Stites (ed.). Human Rights and Transnational Solidarity in Cold War Latin America. Madison: The University of Wisconsin Press, 2013, p. 177-208.

ENSALACO, Mark. Chile under Pinochet. Recovering the Truth. Philadelphia: University of Pennsylvania Press, 2000.

GOLDMAN, Robert. History and Action: The Inter-American Human Rights System and the role of the Inter-American Comission on Human Rights. Human Rights Quarterly, v. 31, n. 4, p. 856-887, 2009.

GRANDIN, Greg. Las instrucciones de las grandes catástrofes: comisiones por la verdad, historia nacional y formación del Estado en Argentina, Chile y Guatemala. Revista Sociohistórica, n. 21-22, p. 205-236, 2007.

GUTIÉRREZ, Cristina Luz García. La recuperación de la "memoria" en las transiciones a la democracia: los casos de Chile y España. Sociedad y movimientos sociales, p. 19-34, 2009. Disponível em: $<$ https://dialnet.unirioja.es/servlet/articulo?codigo $=4484258>$. Acessado em 25 de fevereiro de 2018.

HAU, Boris. Chile, 40 Años de exigencias de verdad y justicia. Razón Crítica, n.4, p. 137-161, 2018. Disponível em: $<$ https://revistas.utadeo.edu.co/index.php/razoncritica/article/view/1275> Acessado em 25 de fevereiro de 2018.

KECK, Margaret E.; SIKKINK, Kathryn. Activists beyond Borders: Advocacy Networks in International Politics. Ithaca and London: Cornell University Press, 1998.

KELLY, Patrick William. The 1973 Chilean coup and the origins of transnational human rights activism. Journal of Global History, v. 8, n. 1, p. 165-186, 2013.

KREFT, Francisca Garretón; LE SAUX, Marianne González; LAUZÁN, Silvana. Políticas Públicas de verdad y memoria en 7 países de América Latina: Argentina, Bolívia, Brasil, Chile, Paraguay, Perú y Uruguai. Santiago: Centro de Derechos 
Humanos, 2011.

LEBLANC, Lawrence J. The OAS and the promotion and protection of Human Rights. The Hague: Martinus Nijhoff, 1977.

LIRA, Elizabeth; LOVEMAN, Brian. Políticas de reparación: Chile 1990-2004. Santiago: Lom Ediciones, 2005.

LUTZ, Ellen.; SIKKINK, Kathryn. The Justice Cascade: The Evolution and Impact of Foreign Human Rights Trials in Latin America, Chicago Journal of International Law, v. 2, n.1, p. 1-33, 2001.

MAIA, Marrielle. Um peso e duas medidas: as interações entre o departamento de Estado dos Estados Unidos e a Comissão Interamericana de Direitos Humanos. In: MAIA, Marrielle; MACIEL, Débora Alves; KOERNER, Andrei (org.). Os Estados Unidos e a Comissão Interamericana de Direitos Humanos: denúncias, Interações, mobilizações. Brasília: FUNAG, 2017, p. 103-132.

MAIA, Marrielle; MACIEL, Débora Alves; KOERNER, Andrei (orgs). Os Estados Unidos e a Comissão Interamericana de Direitos Humanos: Denuncias, Interações, Mobilizações. Brasília: FUNAG, 2017.

MICUS, Annelen. The Inter-American Human Rights System as a Safeguard for Justice in National Transitions: From Amnesty Laws to Accountability in Argentina, Chile and Peru. Leiden and Boston: Brill Nijhoff, 2015.

ORGANIZACIÓN DE LOS ESTADOS AMERICANOS (OEA). Introducción. Disponível em: < http://www.oas.org/es/cidh/mandato/Basicos/intro.asp $>$ Acessado em 02 de abril de 2015.

RISSE, Thomas; SIKKINK, Kathryn. The socialization of international human rights norms into domestic practices: introduction. In: RISSE, Thomas; ROPP, Stephen C.; SIKKINK, Kathryn (eds). The Power of Human Rights: International Norms and Domestic Change. Cambridge: Cambridge University Press, 1999, p. 1-38.

ROMANO, Cesare. The United States and International Courts: getting the CostBenefit Analysis Right. In: ROMANO, Cesare (org.). The Sword and the Scales: The United States and International Courts and tribunals. New York: Cambridge University Press, 2009, p. 419-444.

SALMÓN, Elizabeth. Algumas reflexões sobre o Direito Internacional Humanitário e a justiça transicional: lições da experiência latino-americana. In: REÁTEGUI, Félix (org.). Justiça de transição: manual para a América Latina. Brasília: Comissão de Anistia, Ministério da Justiça, 2011. p. 227-262.

SANTOS, Cecília MacDowell. Ativismo Jurídico Transnacional e o Estado: Reflexões sobre os casos apresentados contra o Brasil na Comissão Interamericana de Direitos Humanos. Sur: Revista Internacional de Direitos 
Humanos, v. 4, n. 7, p. 26-57, 2007.

SCHONSTEINER, Judith; COUSO, Javier. La implementación de las decisiones de los órganos del Sistema Interamericano de Derechos Humanos en Chile: ensayo de un balance. Revista de Derecho Universidad Católica del Norte, v. 22, n. 2, p. 315-355, 2015.

SKAAR, Elin. Human Rights violations and the paradox of democratic transition: A study of Chile and Argentina. Norway: Chr. Michelsen Institute, 1994

. Judicial independence and Human Rights in Latin America. Violations, politics, and prosecutions. New York: Palgrave Macmillan, 2011.

TEITEL, Ruti G. Transitional Justice Genealogy. Harvard Human Rights Journal, v. 16, p. $69-94,2003$.

VAN ZYL, Paul. Promovendo a justiça transicional em sociedades pós-conflito. In: REÁTEGUI, Félix (org.). Justiça de transição: manual para a América Latina. Brasília: Comissão de Anistia, Ministério da Justiça, 2011. p. 47-72.

WILDE, Alexander. Irrupciones de la memoria: la política expresiva en la transición a la democracia en Chile. In: Historizar el pasado vivo en America Latina, 2007.

ZALAQUETT, José. La Comisión de Chile y su misión moral e histórica. In: PNUD. Del dolor a la verdad y a la reconciliación, Bogotá: Editorial El Malpensante S. A, 2006, p, 26-30.

Recebido em 05/03/2018.

Aprovado em 22/05/2018. 